\title{
Comparative study between two types of electrolyte used in the reactive dyeing of cotton
}

\section{REZUMAT - ABSTRACT}

\section{Studiu comparativ între două tipuri de electroliți utilizați în vopsirea cu coloranți reactivi a bumbacului}

Scopul acestui studiu a fost de a compara eficiența a două tipuri de electroliți în vopsirea țesăturilor de bumbac cu coloranți reactivi. S-au studiat factorii care afectează capacitatea de vopsire, cum ar fi concentrația de săruri și performanțele de rezistență a culorii, cum ar fi concentrația substanțelor alcaline. Randamentul tinctorial K/S și rezistența culorii țesăturii vopsite folosind sulfat de sodiu au fost comparabile cu cele obținute cu clorură de sodiu. Cu toate acestea, epuizarea și timpul de fixare au fost mai scurte, iar coeficientul de difuzie a fost mai mic în cazul sulfatului de sodiu.

Cuvinte-cheie: colorant reactiv, țesătură din bumbac, electrolit, epuizare

\section{Comparative study between two types of electrolyte used in the reactive dyeing of cotton}

The aim of this paper was to compare the efficiency of two type of electrolyte in the dyeing of cotton fabrics with reactive dyes. Factors affecting dye ability such as salt concentration, and fastness performances such as alkaliconcentrationwere studied. The colouryield K/S and colour fastness of the dyed fabric using sodium sulfate were comparable to those obtained with sodium chloride. However, the exhaustion and the fixation timewere shorter and the diffusion coefficient was lower in the case of sodium sulfate.

Keywords: reactive dye, cotton fabric, electrolyte, exhaustion

\section{INTRODUCTION}

Cotton is the most natural fibreused in textile industry because it is globally inexpensive, absorbent, breathable and soft. However, different chemical modifications have been studied to improve its wettability, dye ability, chemical affinity, crease recovery, hydrophilicity, and its functional properties. Cotton fibres can be dyed using anionic dyes easily, but usually the common processes of cotton dyeing require large amounts of salt and alkali which mostly remain in the dye bath after the dyeing and may harm the environment [1-3].

Reactive dyes are quite often used for dyeing of cotton fabric as they produce bright and brilliant colour in various shade ranges with excellent colour fastness and are applicable with various application methods. Reactive dyes are applied to cotton in two stages that are exhaustion and fixation. Exhaustion is achieved using salt, preferably Glauber's salt $\left(\mathrm{Na}_{2} \mathrm{SO}_{4}\right)$ or common salt $(\mathrm{NaCl})$ to overcome the negative zeta potential of cotton and promote increased dye-uptake [4-6]. In fact, when cotton fibre is immersed into water, its surface due to hydroxyl ions become also anionic, hence the dye particles and the cellulosic fibre tend to repel each other. The addition of salt creates an electrical positive double layer which hides negative electrostatic charge of cotton surface. This allows the dye to approach the fibre; so that $\mathrm{H}$-bonding and other short-range dye-fibre forces of attraction can operate. The organic dye molecules will have a greater affinity for the fabric than the aqueous solution [7]. The required amount of salt is greater than that required for the adsorption of direct dyes because the reactivedyes have low affinity for the fibre [8]. The quantities of present electrolyte can vary up to $100 \mathrm{~g} / \mathrm{l}$ depending on the required colour deepness, the structure of the dyes or the dyeing recipe [9].The exhausted dyes are fixed to the cotton fabric by using alkalis such as sodium hydroxide $(\mathrm{NaOH})$ and/or sodium carbonate $\left(\mathrm{Na}_{2} \mathrm{CO}_{3}\right)$. Under alkaline conditions reactive dyes react with hydroxyl groups of cellulose, mostly by neucleophilic substitution or addition, to form the covalent bonds.

These strong bonds would be expected to lead to excellent colour fastness laundering. However, the dyes can also react with hydroxyl groups of water so that they are no longer able to react with cellulose. The addition of salt and alkali depends on the deepness of the shade to be produced [10-11]. In reactive dyeing, the process is too lengthy, due to the heat control of dye bath and to portion wise addition of salt and alkali in order to avoid uneven dyeing and maximizing the exhaustion and fixation.

In the present work, a comparative study about two types of salts is elaborated in order to identify their influence in dyeing conditions of cotton fabrics with reactive dye. Different factors affecting dye ability and colour fastness were thoroughly investigated, such as salt and alkali concentrations and type, dyeing temperature and dyeing time. 


\section{EXPERIMENTAL WORK}

\section{Materials}

We have used a Woven twill cotton fabric, scoured, bleached and ready for dyeing with a weight per unit area of $210 \mathrm{~g} / \mathrm{m}^{2}$

The Sumifix Supra Yellow E-XF, a bifunctionnal reactive dye, was provided by Sumitomo Chemical Co., Ltd (Japan). Its chemical formula is specified in figure 1.

The wetting agent and all other reagents, namely sodium chloride, sodium sulfate, sodium hydroxide and sodium carbonate were supplied by the society Chimitex Plus (Tunisia) and were commonly used laboratory reagent grade.

Dyeing process

Cotton fabric weighing $5.0 \mathrm{~g}$ was dyed with a liquorto-goods ratio of $10: 1$ in a dyebath containing $1 \%$ owf of dyes. Dyeing was performed in Ahiba Laboratory dyeing machine (DataColor - USA). The dyeing profile is shown in figure 2.

After dyeing, all the samples were hot rinsed, neutralized with $1 \mathrm{~mL} / \mathrm{L}$ acetic acid during $10 \mathrm{~min}$ at $50^{\circ} \mathrm{C}$, soaped with $2 \mathrm{~mL} / \mathrm{L}$ soap powder solution for $10 \mathrm{~min}$ at $90^{\circ} \mathrm{C}$ and then rinsed thoroughly with tap water and air-dried at room temperature [12].

\section{Conductivity measurements}

The conductivity was measured using the conductivity meter Sension+ EC71 (Hach - USA) and recorded in $\mathrm{mS} / \mathrm{cm}$.

\section{Colour measurements}

The relative colouryield of dyed fabrics expressed as $\mathrm{K} / \mathrm{S}$ was measured by the light reflectance technique

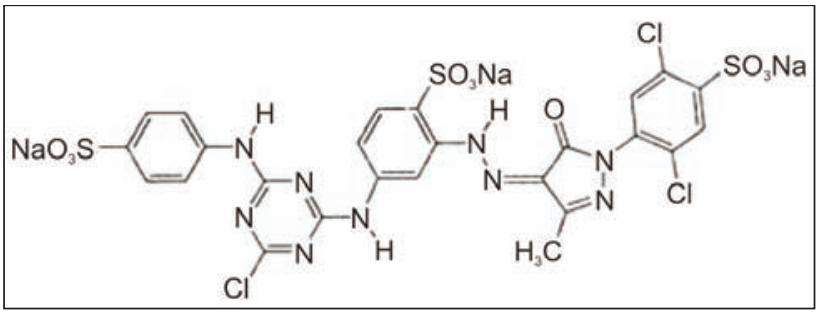

Fig. 1. Chemical structure of the used dye $\left(\lambda_{\max }=418 \mathrm{~nm}\right)$

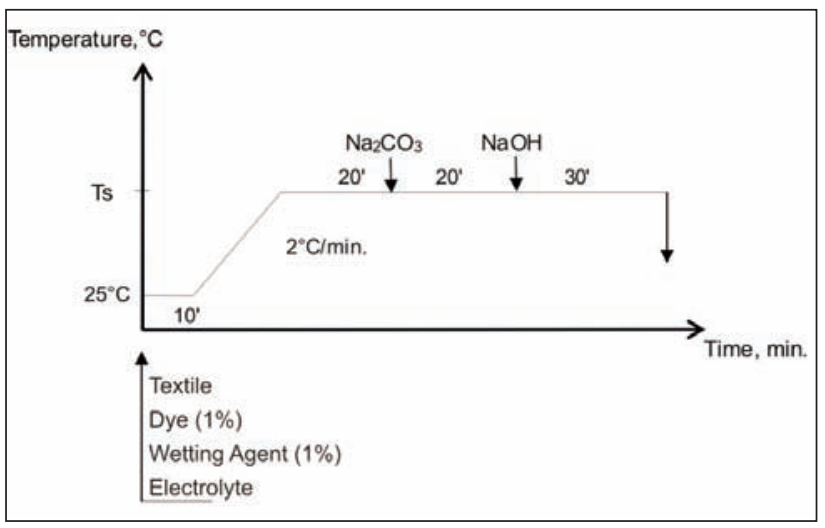

Fig. 2. Dyeing process of cotton fabric with reactive dye using the Kubulka-Munk equation. The reflectance of dyed fabrics was measured on Spectra Flash SF600 spectrophotometer with data Master 2.3 software (Data Color International, USA).

The dye exhaustion rate $(\% E)$ was calculated according to the following equation:

$$
\% E=\left[\frac{A_{0}-A_{f}}{A_{0}}\right] \times 100
$$

Where $A_{0}$ and $A_{f}$ are, respectively, the absorbance of the dyebath before and after dyeing at $\lambda_{\max }$ of the dye used. The absorbance was measured on Biochrom Libra S6 visible spectrophotometer.

\section{Colour fastness testing}

The dyed samples were tested for colour fastness according to standard methods: $1^{\circ}$ ) ISO 105-C06: 2010 Colour fastness to domestic and commercial laundering, $2^{\circ}$ ) ISO $105-X 12: 1987$ colour fastness to rubbing, and $3^{\circ}$ ) ISO 105-B02:2014: Colour fastness to artificial light: Xenon arc fading lamp test.

\section{Dyeing Kinetic study}

The study of the Kinetics concerns the mechanism by which the dyeing processes attempts to reach the equilibrium state and how long it takes. One of the most fundamental processes that control the rate at which many distinct periods or stages in the whole process occur is the diffusion.

In our case, considering that " $\mathrm{C}$ " stands for the concentration of dye particles which is described as:

$$
C(x, y, z, t)
$$

"J" stands for the course density of dye particles which is described as:

$$
J(x, y, z, t)
$$

The Fick's law is empirical in that it assumes proportionality between the diffusion flux and the concentration gradient [13]. It describes the diffusion processes of the dye by the following equation:

$$
J=-D \operatorname{grad} C
$$

Or, we know that the conservation of the particles gives the following mathematical equation:

$$
\operatorname{div} J=-\frac{\partial C(x, y, z, t)}{\partial t}
$$

Combining equation 3 and 4, we obtain the following mathematical model:

$$
\frac{\partial C(x, y, z, t)}{\partial t}=D \Delta C
$$

In order to resolve this equation, Crank proposed a simplified solution to this Fick's law of diffusion [14]. The specific surface of the fibre appears in this solution:

$$
\frac{C_{f, t}}{C_{f, \infty}}=A \sqrt{t}
$$

where:

$$
A=\frac{4}{r \sqrt{\pi}} \sqrt{D}
$$


$D\left(\mathrm{~cm}^{2} / \mathrm{s}\right)$ is the diffusion coefficient, $C$ is the dye concentration and $r$ is the radius of the fibre $(m)$. In the case of the cotton reactive dyeing, the equation can be simplified as following:

$$
\frac{E_{t}}{E_{\infty}}=\frac{4}{r \sqrt{\pi}} \sqrt{D}\left(t^{1 / 2}\right)
$$

In our study, we use the Equation (9) to determine the diffusion coefficient. It is sufficient to determine the slope of the curve of $E_{t} / E_{\infty}$ versus $t^{1 / 2}$ to calculate the diffusion coefficient $D$. [15]

\section{RESULTS}

\section{Effect of dyebath temperature on exhaustion}

Figures 3 and 4 show, respectively, the effect of dyeing temperature on dyebath conductivity and on exhaustion of the dye on the fibres. The conductivity increases with the temperature and stabilize from $50{ }^{\circ} \mathrm{C}$. As temperature increases, the energy gained by the molecules in the medium (electrolyte) increases and hence the ions are in a higher energy state. This energy will be converted into kinetic energy and so, the mobility increases. Hence the conductivity increases. The conductivity of Sodium Sulfate is

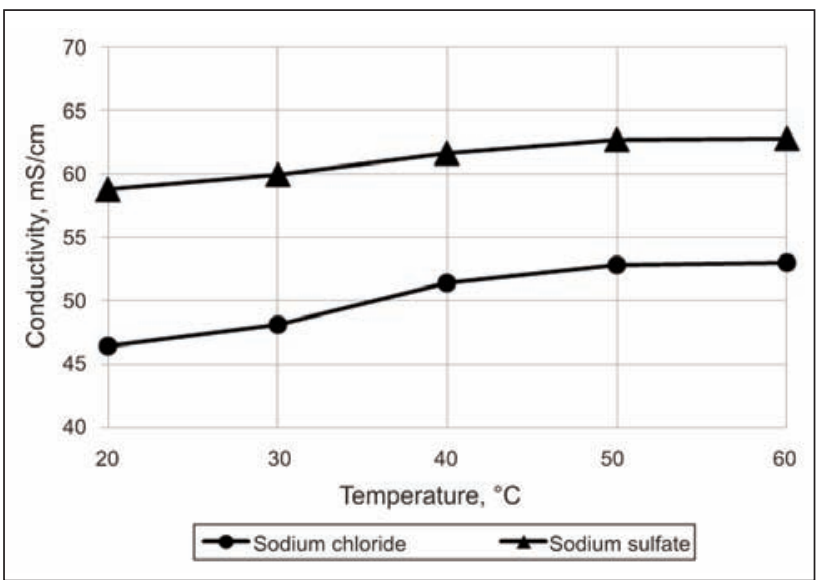

Fig. 3. Effect of dyeing temperature on bath conductivity

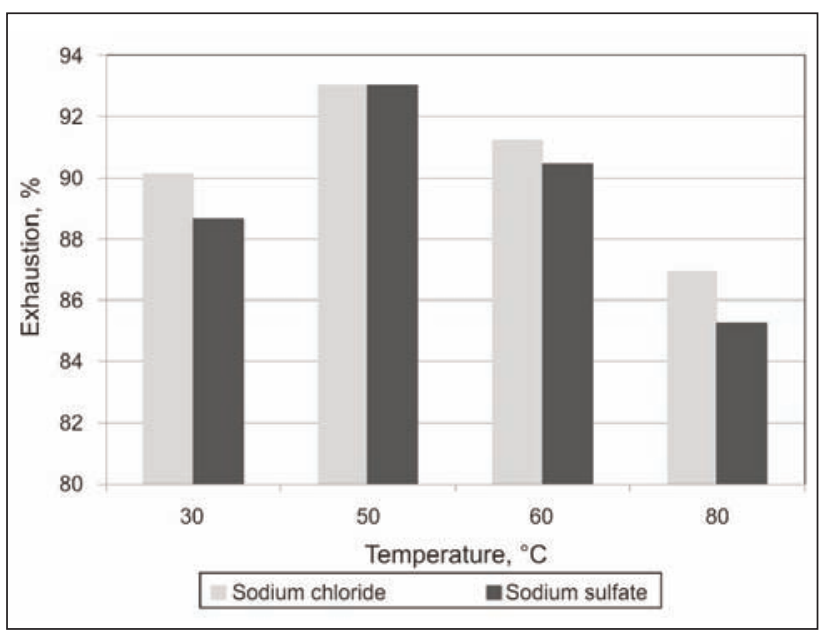

Fig. 4. Effect of dyeing temperature on the exhaustion of the dye on cotton fabric higher than that of Sodium Chloride irrespective the temperature. In fact, conductivity depends on the concentration of charge carriers (ions) in the aqueous solution. When one mole of $\mathrm{NaCl}$ dissolves it produces two ions. But when one mole of $\mathrm{Na}_{2} \mathrm{SO}_{4}$ dissolves it produces three ions. Thus fewer moles of ions are produced by the $\mathrm{NaCl}$ solution and so we would expect its conductivity to be smaller.

An increase in the dye exhaustion on cotton fabric is observed as the dyeing temperature increased from 30 to $50^{\circ} \mathrm{C}$. However, increasing the temperature from 50 to $80^{\circ} \mathrm{C}$ was accompanied by a successive decrease in the exhaustion values for both electrolytes. It is known that increasing temperature favours cotton fibre swelling, which leads to a higher dye uptake. The Exhaustion is slightly better when sodium chloride is used as electrolyte.

These results indicate that $50^{\circ} \mathrm{C}$ is the suitable temperature for this reactive dye, above which the hydrolysis of the dye occurs resulting in a decrease in the dye uptake. This vinyl sulfone dye, actually, belongs to the group of alkali-controllable reactive dyes, which display optimum fixation temperature between 40 and $60^{\circ} \mathrm{C}$ and which are characterized by low exhaustion in electrolyte solution before the addition of alkali. Such dyes have high reactivity and require careful alkali addition (portion wise) to achieve level dyeing [16]. This temperature will be considered as optimal for the rest of the study.

\section{Optimization of electrolyte and alkali concentrations}

Different factors can affect the dye ability and fastness properties of reactive dyeing of cotton fabrics. The most important ones are electrolyte concentration and alkali concentration. A factorial experimental design was used to study the main effects and the interaction effects between these two operational parameters. The experimental design and the statistical analysis of experiments were carried out using the statistical software Minitab 14. The analysis of variance was applied to evaluate the significance of the effect of all variables and their interactions on the response. P-values lower than 0.05 indicate that the model and the terms are statistically significant [17]. The factors considered in this study are: Electrolyte concentration (20 and $40 \mathrm{~g} / \mathrm{L}$ ), Sodium carbonate concentration ( 3 and $7 \mathrm{~g} / \mathrm{L}$ ) and Sodium hydroxide concentration $(0.7$ and $1 \mathrm{~mL} / \mathrm{L})$. These minimum and maximum values are indicated by the technical data sheet of the dye. The experimental result or the response to treat is the colour yield parameter (K/S). The study was realized for the two electrolytes: Sodium Sulfate and Sodium chloride

The experimental surface plan to modelize is described in table 1.

A main effect occurs when the mean response changes across the levels of a factor. Main effects plots could be used to compare the relative strength of the effects across factors. Main effect diagrams described in figures 5 and 6 show the behaviour of 


\begin{tabular}{|c|c|c|c|}
\hline \multicolumn{5}{|c|}{ LEVELS OF STUDIED VARIABLE } \\
\hline Test $\mathbf{N}^{\circ}$ & $\begin{array}{c}\text { Electrolyte } \\
(\mathbf{g} / \mathbf{L})\end{array}$ & $\begin{array}{c}\mathbf{N a}_{\mathbf{2}} \mathbf{C O}_{\mathbf{3}} \\
\mathbf{( g / L )}\end{array}$ & $\begin{array}{c}\mathbf{N a O H} \\
(\mathbf{m L} / \mathbf{L})\end{array}$ \\
\hline 1 & 20 & 3 & 0.7 \\
\hline 2 & 20 & 3 & 1 \\
\hline 3 & 20 & 7 & 0.7 \\
\hline 4 & 20 & 7 & 1 \\
\hline 5 & 40 & 3 & 0.7 \\
\hline 6 & 40 & 3 & 1 \\
\hline 7 & 40 & 7 & 0.7 \\
\hline 8 & 40 & 7 & 1 \\
\hline
\end{tabular}

VARIANCE ANALYSIS FOR THE COLOUR YIELD PARAMETER (K/S), WITH NaCI AS A SALT

\begin{tabular}{|l|c|c|c|c|c|}
\hline Source & DL & Adj SS & Adj MS & F & P \\
\hline Model & 3 & 1.7204 & 0.57348 & 22.72 & 0.006 \\
\hline Linear & 3 & 1.7204 & 0.57348 & 22.72 & 0.006 \\
\hline$[\mathrm{NaCl}]$ & 1 & 0.8320 & 0.83205 & 32.97 & 0.005 \\
\hline$\left[\mathrm{Na}_{2} \mathrm{CO}_{3}\right]$ & 1 & 0.1922 & 0.19220 & 7.62 & 0.041 \\
\hline$[\mathrm{NaOH}]$ & 1 & 0.6962 & 0.69620 & 27.59 & 0.006 \\
\hline Error & 4 & 0.1010 & 0.2524 & & \\
\hline Total & 7 & 1.8214 & & & \\
\hline
\end{tabular}

hydroxide concentration have also an effect on colour yield which is non-negligible in the case where $\mathrm{NaCl}$ is used as an exhaustion agent.

An interaction between factors occurs when the change in response from the low level to the high level of one factor is different from the change in response at the same two levels of a second factor. Hence, the effect of one factor is dependent upon a second factor. Interactions plots could be used to compare the relative strength of the effects across factors. As seen in figures 7 and 8 , there is no interaction between different parameters. The only obvious interaction was between the two alkalis in the case where $\mathrm{Na}_{2} \mathrm{SO}_{4}$ was used as a salt.

In the case of $\mathrm{NaCl}$ as a salt, the regression analysis of the experimental surface plan by a quadratic model leads to the following equation:

$$
\mathrm{K} / \mathrm{S}=3.773+0.03225[\mathrm{NaCl}]
$$

$+0.0775\left[\mathrm{Na}_{2} \mathrm{CO}_{3}\right]++1.967[\mathrm{NaOH}]$

Fig. 5. Analysis of main effects plot of the colour yield $(K / S)$ in the case where $\mathrm{NaCl}$ is used as electrolyte

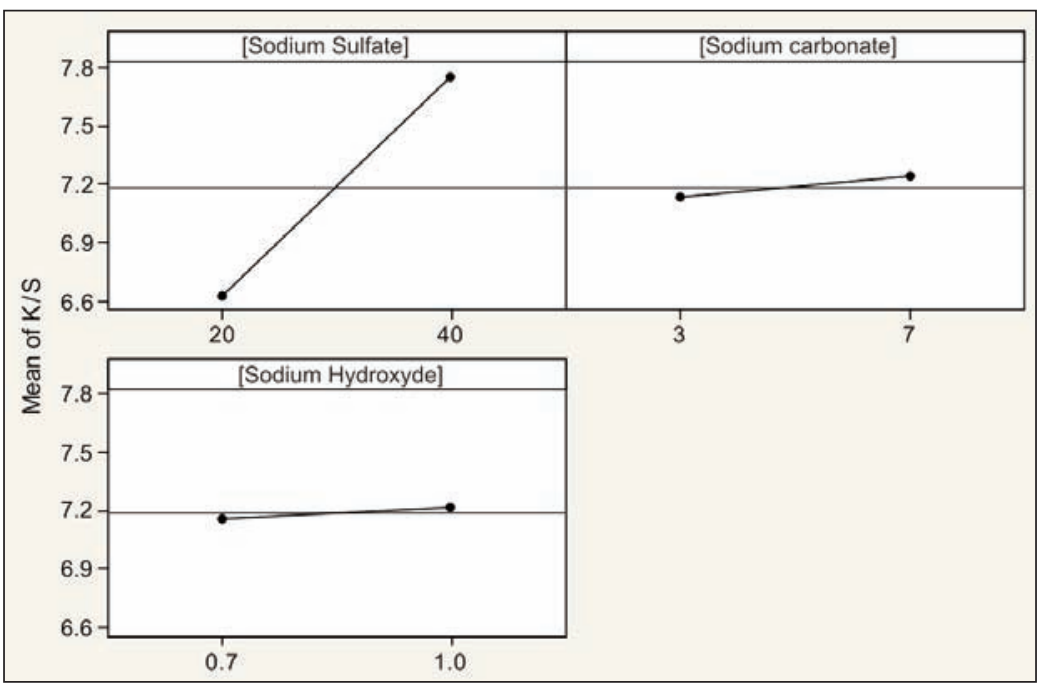

Fig. 6. Analysis of main effects plot of the colour yield $(\mathrm{K} / \mathrm{S})$ in the case where $\mathrm{Na}_{2} \mathrm{SO}_{4}$ is used as electrolyte
For the regression equation of the dyeing quality parameter $(K / S)$, it was found that the squared multiple correlation coefficient $R^{2}$ is equal to $94.46 \%$. It can be deduced that the model obtained has a very good predictability. According to table 2, the variance analysis (ANOVA) proves that, for the dyeing parameter, the regression model obtained is highly significant $(p=0.006)$. Moreover, there is a significant linear effect $(p=0.006)$ When Sodium Sulfate was used as a salt, the following equation is obtained:

$$
\begin{aligned}
& K / S=5,212+0.05650\left[\mathrm{Na}_{2} \mathrm{SO}_{4}\right]+ \\
& +0.0250\left[\mathrm{Na}_{2} \mathrm{CO}_{3}\right]+0.183[\mathrm{NaOH}]
\end{aligned}
$$

For the regression equation of the dyeing quality parameter $(K / S)$, the interaction between the two alkalis was neglected because the value of $p$ 


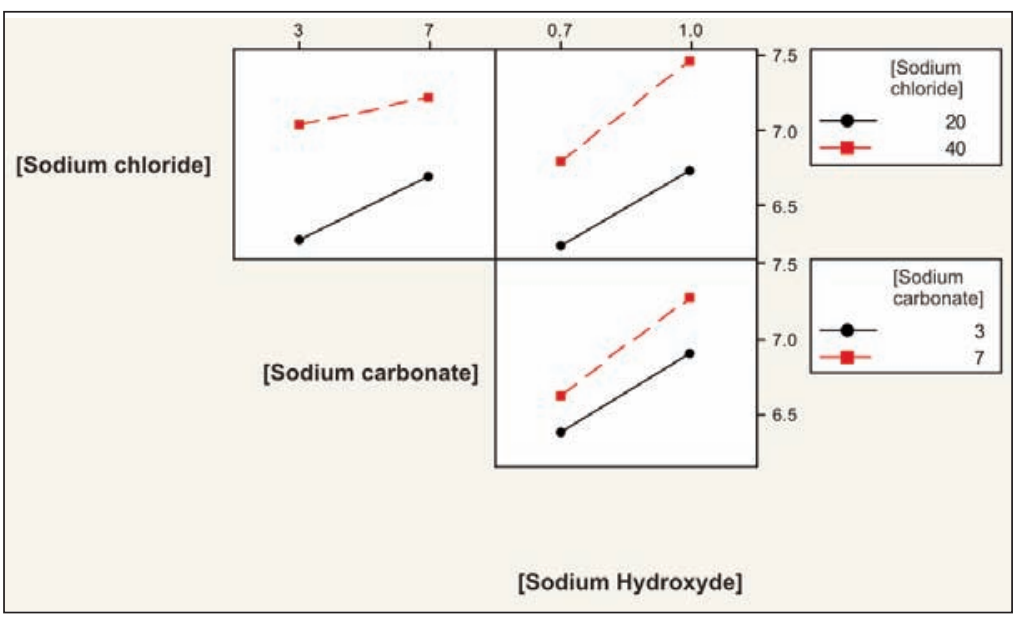

Fig. 7. Analysis of interaction plot of the colour yield $(\mathrm{K} / \mathrm{S})$ in the case where $\mathrm{NaCl}$ is used as electrolyte

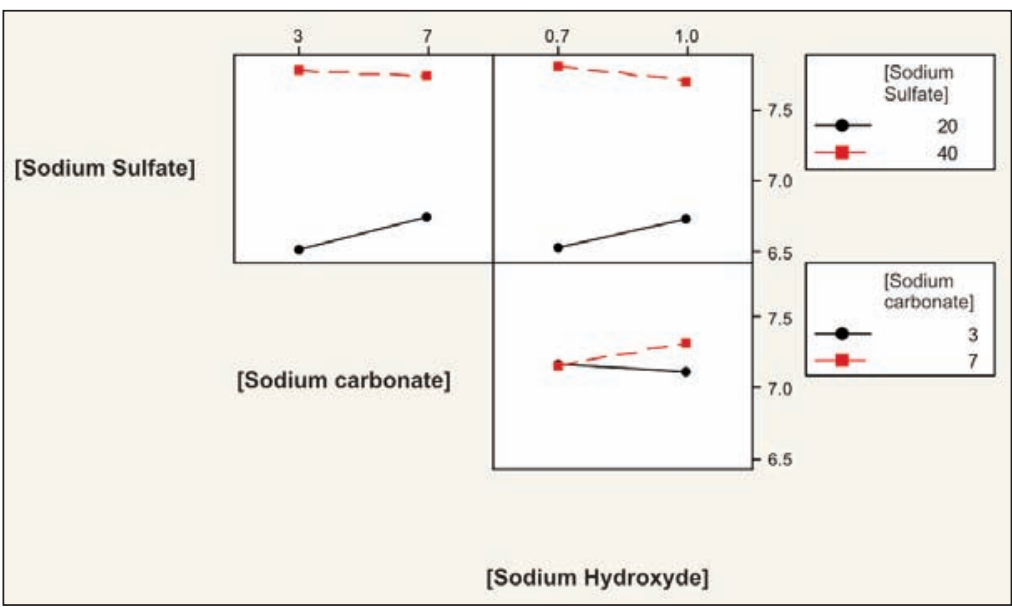

Fig. 8. Analysis of interaction plot of the colour yield $(\mathrm{K} / \mathrm{S})$ in the case where $\mathrm{Na}_{2} \mathrm{SO}_{4}$ is used as electrolyte for the response. Response optimizer provides an optimal solution for the input variable combinations [18]. The desired Response optimization described in figures 9 and 10 shows that optimal experimental conditions for obtaining the highest colouryieldare a salt concentration of $40 \mathrm{~g} / \mathrm{L}, \mathrm{Na}_{2} \mathrm{CO}_{3}$ concentration of $7 \mathrm{~g} / \mathrm{L}$ and $\mathrm{NaOH}$ concentration of $1 \mathrm{ml} / \mathrm{L}$.

\section{Dyeing kinetics study}

The slope of a dyeing exhaustion curve defines the rate of dyeing at any instant during the dyeing process. Equilibrium is reached when no more dye is taken up by the fibres. There is a balance between the rate of dye absorption and desorption. Figure 11 shows the evolution of the \% exhaustion of the reactive dye versus dyeing time for the two type of salt. The maximal exhaustion is obtained after 70 minutes at $50^{\circ} \mathrm{C}$. The dyeing exhaustion rate is slightly better when sodium sulfate is used as a salt. Dyeing conditions that can be recovered from these curves are described in table 4. The half-dyeing time ( $\mathrm{t} 1 / 2)$, which is the time taken for the fibre to adsorb half as much dye as is adsorbed at equilibrium, is considered as a convenient measure of the velocity of dyeing [19]. It can allow the determination of Exhaustion and Fixation time. The exhaustion rate is better when sodium sulfate is used as electrolyte. was superior to 0.005 . The model obtained has a very good predictability as the squared multiple correlation coefficient $R^{2}$ was equal to $93.21 \%$.

According to table 3 , the variance analysis (ANOVA) proves that, for the dyeing parameter, the regression model obtained is highly significant $(p=0.008)$. Moreover, there is a significant linear effect ( $p=$ 0.008).

Many designed experiments involve determining optimal conditions that will produce the "best" value

Table 3

\begin{tabular}{|c|c|c|c|c|c|}
\hline \multicolumn{6}{|c|}{$\begin{array}{l}\text { VARIANCE ANALYSIS FOR THE COLOUR YIELD } \\
\text { PARAMETER (K/S), WITH } \mathrm{Na}_{2} \mathrm{SO}_{4} \text { AS A SALT }\end{array}$} \\
\hline Source & DL & Adj SS & Adj MS & $\mathbf{F}$ & $\mathbf{P}$ \\
\hline Model & 3 & 2.57985 & 0.85995 & 18.31 & 0.008 \\
\hline Linear & 3 & 2.57985 & 0.85995 & 18.31 & 0.008 \\
\hline$\left[\mathrm{Na}_{2} \mathrm{SO}_{4}\right]$ & 1 & 2.55380 & 2.55380 & 54.37 & 0.002 \\
\hline$\left[\mathrm{Na}_{2} \mathrm{CO}_{3}\right]$ & 1 & 0.02000 & 0.02000 & 0.43 & 0.048 \\
\hline$[\mathrm{NaOH}]$ & 1 & 0.00605 & 0.00605 & 0.13 & 0.038 \\
\hline Error & 4 & 0.18790 & 0.04698 & & \\
\hline Total & 7 & 2.76775 & & & \\
\hline
\end{tabular}

industroia textillă
Fig. 9. Response optimization of the colour yield $(\mathrm{NaCl}$ as a salt)

\begin{tabular}{|cc|ccc|}
\hline Optimal & $\mathrm{Hi}$ & {$\left[\mathrm{Na}_{2} \mathrm{SO}_{4}\right]$} & {$\left[\mathrm{Na}_{2} \mathrm{CO}\right]$} & {$[\mathrm{NaOH}]$} \\
$\mathrm{D}$ & $\mathrm{Cu}$ & 40.0 & 7.0 & 1.0 \\
0.97571 & Lur & {$[40.0]$} & {$[7.0]$} & {$[1.0]$} \\
& Lo & 20.0 & 3.0 & 0.70 \\
\hline \hline KIS & & & \\
Maximum & & & \\
$y=7.830$ & & & \\
$\mathrm{~d}=0.97571$ & & & \\
& & & & \\
\cline { 2 - 4 } & & & & \\
\hline
\end{tabular}

Fig. 10. Response optimization of the colour yield $\left(\mathrm{Na}_{2} \mathrm{SO}_{4}\right.$ as a salt) 


\begin{tabular}{|c|c|c|c|c|c|}
\hline \multicolumn{7}{|c|}{ DYEING TIME FOR THE TWO SALTS } \\
\hline Type of salt & $\begin{array}{c}\text { Exhaustion } \\
(\%)\end{array}$ & $\begin{array}{c}\mathbf{t}_{\mathbf{1 / 2}} \\
(\mathbf{m i n})\end{array}$ & $\begin{array}{c}\text { Exhaustion time } \\
(\mathbf{m i n})\end{array}$ & $\begin{array}{c}\text { Fixation time } \\
(\mathbf{m i n})\end{array}$ & $\begin{array}{c}\mathbf{D}_{\text {moy }} \\
\left.\mathbf{c m}^{2} / \mathbf{s}\right) \mathbf{1 0}^{-11}\end{array}$ \\
\hline$[\mathrm{NaCl}]$ & 88.52 & 6 & 12 & 24 & 0,7989 \\
\hline$\left[\mathrm{Na}_{\mathbf{2}} \mathrm{SO}_{\mathbf{4}}\right]$ & 90.66 & 5 & 10 & 20 & 0,8160 \\
\hline
\end{tabular}

\begin{tabular}{|c|c|c|c|c|c|}
\hline \multicolumn{7}{|c|}{ COLOUR FASTNESS } & ISO 105-B02 \\
\hline \multirow{2}{*}{} & & $\begin{array}{c}\text { ISO 105-C06 } \\
\text { (C1S test method) }\end{array}$ & \multicolumn{2}{c|}{ ISO 105-X12 } & Light \\
\cline { 2 - 6 } & & Washing $\left(60^{\circ} \mathrm{C}\right)$ & Dry Rubbing & Wet Rubbing & 5 \\
\hline \multirow{2}{*}{ Electrolyte } & $\mathrm{NaCl}$ & 5 & $4 / 5$ & 4 & 5 \\
\cline { 2 - 6 } & $\mathrm{Na}_{2} \mathrm{SO}_{4}$ & 5 & $4 / 5$ & 4 & 5 \\
\hline
\end{tabular}

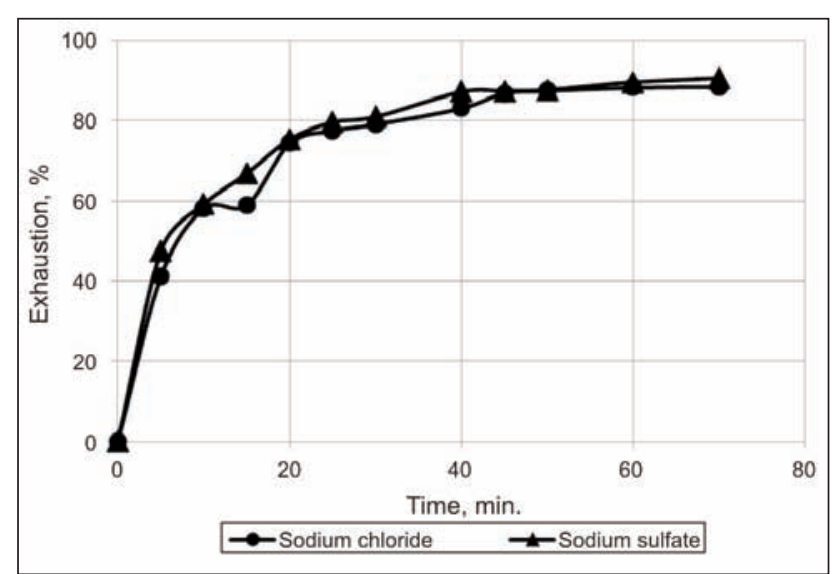

Fig. 11. Dyeing exhaustion curves for the two type of salt $\left(\mathrm{NaCl}\right.$ and $\left.\mathrm{Na}_{2} \mathrm{SO}_{4}\right)$

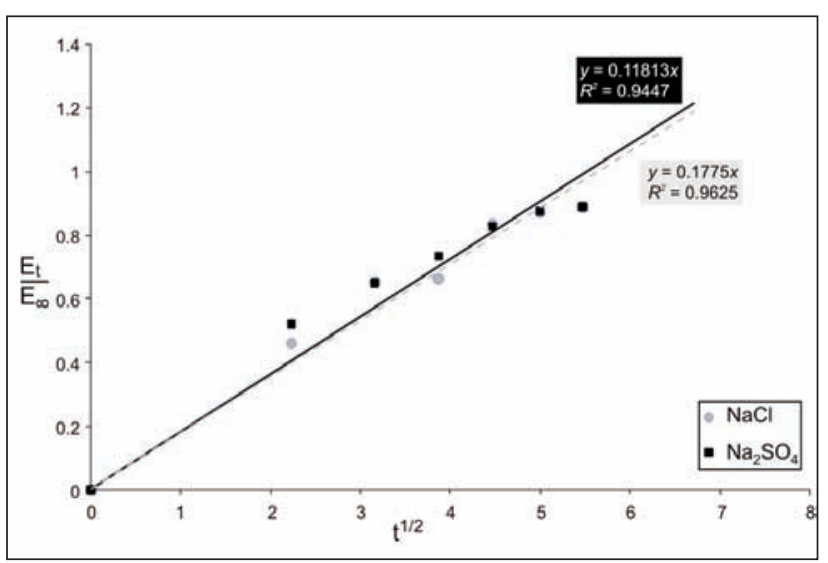

Fig. 12. Influence of salt type $\left(\mathrm{NaCl}\right.$ and $\left.\mathrm{Na}_{2} \mathrm{SO}_{4}\right)$ on the coefficient of diffusion of the dye

The exhaustion and fixation time are shorter in this case.

The diffusion coefficient $\mathrm{D}$ can be deduced from figure (12). It is clear that the diffusion is better in the case of Sodium Sulfate as electrolyte. The probable explanation is that addition of the sodium sulfate lowers the repulsion more than the sodium chloride by imparting more quantity of oppositely charged ion with the charged dye anion. Compared to sodium chloride, the presence of the sodium sulfate in the dyebath decreases much more the membrane potential of cellulose which reduces of the repellency of cellulose and dye particles with the same charges and consequently improves dye ability.

\section{Colour fastness results}

The results summarized in table 5 demonstrate that whatever the nature of electrolyte, no difference in colour fastness was observed.

\section{CONCLUSIONS}

The influence of two types of electrolyte (sodium sulfate and sodium chloride) on the quality of a reactive dyeing on cotton fabric was studied. Obtained results have shown that the colour yield $\mathrm{K} / \mathrm{S}$ and colour fastness of the dyed fabric using sodium sulfate were comparable to those obtained with sodium chloride. Sodium sulfate overcomes more efficiently the negative zeta potential of cotton than sodium chloride; that is why the diffusion coefficient is lower in this case, and the exhaustion time is shorter. Response surface methodology was employed to model, analyze and optimize electrolyte and alkali concentration. The optimum concentrations for obtaining highest colour yield on reactive dyeing of cotton fabric were a salt concentration of $40 \mathrm{~g} / \mathrm{L}, \mathrm{Na}_{2} \mathrm{CO}_{3}$ concentration of 7 $\mathrm{g} / \mathrm{L}$ and $\mathrm{NaOH}$ concentration of $1 \mathrm{ml} / \mathrm{L}$.

\section{ACKNOWLEDGEMENTS}

The author would like to express sincere gratitude to the direction and the staff of Chimitex Plus for their support and help. 


\section{BIBLIOGRAPHY}

[1] Hajji, S.A., Qavamnia, S., \& Bizhaem, F.K. Salt free neutral dyeing of cotton with anionic dyes using plasma and chitosan treatments. In: Industria Textila, 2016, vol. 67, pp. 109-113.

[2] Zhang, F., Chen, Y., Lin, H., Wang, H., Zhao, B., HBP-NH 2 grafted cotton fibre: Preparation and salt-free dyeing properties. In: Carbohydrate Polymers, 2008, vol. 74, issue 2, pp. 250-256

[3] Haji, A., Eco-Friendly Dyeing and Antibacterial Treatment of Cotton. In: Cellulose Chemistry and Technology, 2013, vol. 47, pp. 303-308.

[4] Trotman, E.R. Dyeing and chemical technology of textile fibres, Nottingham: 6th ed, 1984.

[5] Tarbuk, A., Grancaric, A. and Leskovac, M. Novel cotton cellulose by cationisation during the mercerisation process - Part 1: Chemical and morphological changes. In: Cellulose, 2014, vol. 21, pp. 2167-2179.

[6] Ristic, N. \& Ristic, L. Cationic modification of cotton fabrics and reactive dyeing characteristics. In: Journal of Engineered fibers and fabrics, 2012, vol. 7, pp. 113-121.

[7] Cocket, S. \& Hilton, K. Dyeing of cellulose fibre and related Process, London: Leonard Hill books Ltd, 1961, p. 212.

[8] Lim, S. \& Hudson, S.H. HYPERLINK "http://onlinelibrary.wiley.com/doi/10.1111/j.1478-4408.2004.tb00215.x/full" Application of a fibre-reactive chitosan derivative to cotton fabric as a zero-salt dyeing auxiliary. In: Coloration Technology, 2004, vol. 120, issue 3, pp. 108-113.

[9] Madaras, G.W., Parish, G. \& Shore, J. Batchwise dyeing of woven cellulosic fabrics, Bradford: SDC, 1993.

[10] Agarwal, B. \& Bhattacharya, S. Possibilities of polymer-aided dyeing of cotton fabric with reactive dyes at neutral pH. In: Journal of applied polymer science, 2010, vol. 118, pp. 1257-1269.

[11] Chinta, S. \& Vijayakumar, S. Technical facts and figures of reactive dyes used in textiles. In: International Journal of Managment Science, 2013, vol. 4, pp. 308-312.

[12] Hamdaoui, M., Turki, S., Romdhani, Z. \& Halaoua, S. Effect of reactive dye mixtures on exhaustion values. In: Indian Journal of fibre \& Textile Research, 2013, vol. 38, pp. 405-409.

[13] Fick, A. Ueber diffusion. In: Annalen der Physik, 1855, vol. 170, p. 59.

[14] Crank, J. \& Park, G., Diffusion in polymers, London: Academin Press, 1968.

[15] Hamdaoui, M., Charfi, A. \& Khoffi, F. Study of the dyeing kinetics: Influence of pre-treatments and woven fabric structure. In: Open Acces Scientific Reports, 2012, vol. 1, Issue 10.

[16] Burkinshaw, S. Physico-chemical aspects of textile coloration, Bradford: John Wiley \& Sons in association with the Society of Dyers and Colorists, 2016.

[17] Haji, A. and Qavamnia, S.S., Response surface methodology optimized dyeing of wool with cumin seeds extract improved with plasma treatment. In: Fibers and Polymers, 2015, vol. 16, pp. 46-53.

[18] Meyers, R. \& Montgomery, D. Response surface methodology: Process and Product Optimization using designed experiments, New York: John Wiley \& sons, 1995.

[19] Boulton, J. \& Reading, B. Classification of direct dyes with respect to the production of level dyeings on viscose rayon. In: Journal of the society of dyers and colourists, 1934, vol. 50, pp. 381-385.

\section{Authors:}

\section{AYDA BAFFOUN}

University of Monastir

Textile Materials and Processes Research Unit MPTex

National Engineering School of Monastir

Monastir, Tunisia

e-mail: aydabaffoun@gmail.com 